\section{EDITOR:}

- C.J. Eales, PhD

University of the Witwatersrand

\section{Assistant Editor:}

- A. Stewart, MSc

University of the Witwatersrand

\section{EDITORIAL BOARD:}

NATIONAL MEMBERS

- S.L. Amosun, PhD

University of the Western Cape

- P. Gounden, $\mathrm{PhD}$

University of Durban-Westville

- M. Papadoupolos, MSc

University of Pretoria

- M. Faure, MPhil

University of Stellenbosch

- N. Mbambo, MSc

MEDUNSA

\section{INTERNATIONAL MEMBERS}

- A. Akinpelu, PhD

University College Hospital, Ibadan, Nigeria

- T.H.A. Kolobe, PhD

University of Illinois, Chicago

- K. Shepard, PhD

Temple University, Philadelphia

- C. Partridge, $\mathrm{PhD}$

University of Kent, Canterbury

\section{Review Panel 2002:}

- Bester, Ria

- Bischof, Faith

- Bowerbank, Pat

- Crocker, Jenny

- Crous, Lynette

- David, Helen

- Diener, Ina

- Eisenberg, Masha

- Eksteen, Carina

- Fearnhead, Lynn

- Frieg, Annette

- Giraud, Jill

- Hunter, Linda

- Irwin-Carruthers, Sheena

- Jelsma, Jennifer

- Kemp, Stephanie

- M'Kumbuzi, Vyvienne

- Mothabeng, Joyce

- Mpofu, Ratie

- Naidu, Prinola

- Paulsen, Tom

- Potterton, Joanne

- Puckree, Lina

- Van Rooijen, Tania

\title{
THE DIFFERENCE IS IN OUR HANDS?
}

$\mathrm{P}$ hysiotherapists claim that the "difference is in our Hands". Does that mean that they can literally influence the outcome of disease and disability by using their hands and that their profession is one based mainly on physical interactions or does it mean that in order to make a difference for their patients they will use their professional initiative? Is our profession a 'physical' one only or may we use other methods and modalities in order to bring about a positive result? Do we administer drugs through massage, electrotherapy and inhalation only or should we actually prescribe drugs for their systemic effect as well?

Since the inception of the profession certain medications have been administered to patients by means of electrotherapy. It is especially in the treatment of skin conditions that we have administered various medications. It is also quite true to say that we cannot function adequately in respiratory physiotherapy if we don't have access to bronchodilators and mucolytics in inhalant solutions. In the treatment of sports injuries our treatments are often enhanced by non steroidal anti-inflammatory drugs, and so the list goes on.

Often prescription medication forms an integral part of the treatment regimen. What is of great concern however is that the process of administering drugs to patients has never been approved by the Health Professions Council of South Africa. What has even more serious implications for the profession is that, should physiotherapists want to prescribe medications for patients, their entire scope of practice would have to be revisited. If we believe that this is the way forward there would have to be a strong mandate from the profession to proceed in this way.

So where do we take it from here? We have obtained the lists of medications commonly administered by physiotherapists from all the special interest groups. We will seek formal approval from the Health Professions Council of South Africa to administer these medications. Once we have such approval we will approach the Medicines Control Council to formalize the process. We will have to reassure them that physiotherapists have the knowledge required to administer such medication and that they could function safely in this regard. Only then will we be able to turn our attention to the prescription of medications. We will then have to make certain serious decisions as a profession as to whether the difference is indeed in our hands or whether we want to change the profile of Physiotherapy. If we did indeed want to proceed on the route of prescribing certain medications then the minimum requirement of 45 hours of pharmacology would certainly not suffice and the insurance cover of practitioners would be dramatically increased.

We are fortunate to include in this publication an article by Professor van der Bijl et al on aspects of the use of non-steroidal anti-inflammatory drugs by Physiotherapists. Read it with care and let us think this through again. The editor would gladly publish your opinions on the role physiotherapists should play in the administration and prescription of medicines.

SIELIE EALES (EDITOR) 